\title{
On Forchheimer's Model of Dominant Firm Price Leadership
}

\author{
Attila Tasnádi \\ Department of Mathematics, Budapest University of Economic Sciences \\ and Public Administration, H-1093 Budapest, Fővám tér 8, Hungary*
}

January 5, 2004.

Appeared in Economics Letters, 84(2004), p. 275-279.

(C)Elsevier Science S.A.

\begin{abstract}
We show that in a simple price-setting game with one large firm and many small firms the large firm does not accept the role of the price leader.
\end{abstract}

Keywords: Forchheimer; Dominant firm; Price leadership

JEL classification: D43; L13

\section{Introduction}

Deneckere and Kovenock (1992) gave a game-theoretic foundation of Forchheimer's model of dominant-firm price leadership in the framework of a capacity constrained Bertrand-Edgeworth duopoly. According to Forchheimer's model we have one large firm and many small firms in the market. The large firm is assumed to set the price in the market, while the small firms act as price takers.

We gave another microfoundation of Forchheimer's model in a previous paper (Tasnádi, 2000) in a market with one 'large' firm and infinitely many 'small' firms, where we assumed strictly convex cost functions and the large firm to be the exogenously given first mover. Now we want to investigate whether the large firm accepts the role of the first mover. Since analyzing the question of endogenous timing in the market with infinitely many firms leads to a quite difficult task, we consider a market with only finitely many firms.

We show that we obtain a game-theoretic foundation of Forchheimer's model if the large firm is the exogenously given first mover (Proposition 1). Hence, to obtain an implementation in subgame-perfect Nash equilibrium in case of strictly convex cost functions it is not necessary to take infinitely

\footnotetext{
*Telephone: (+36 1) 4566782, E-mail: attila.tasnadi@math.bke.hu
} 
many small firms. However, analyzing a simple two-period timing game, we obtain that the large firm does not accept the role of the first mover (Theorem 1). This contradicts our intuition that a price-setting game with one large firm and sufficiently many small firms should lead to Forchheimer's model, and we conjecture that other variables beside price are needed to derive Forchheimer's model.

\section{The framework}

We impose the following assumptions on the demand function.

Assumption 1. $D: \mathbb{R}_{+} \rightarrow \mathbb{R}_{+}$is continuous, strictly decreasing on $[0, b]$, continuously differentiable on $(0, b)$, and equal to zero on $[b, \infty)$.

We shall denote the set of firms by $\Omega:=\{0,1, \ldots, n\}$ and their cost functions by $c_{0}, c_{1}, \ldots, c_{n}$.

Assumption 2. For all $i \in \Omega$ the cost functions $c_{i}: \mathbb{R}_{+} \rightarrow \mathbb{R}_{+}$are twice continuously differentiable, strictly increasing and strictly convex.

The competitive supply, henceforth briefly supply, of firm $i \in \Omega$ is given by $s_{i}(p)=\arg \max _{q \geq 0} p q-c_{i}(q) .{ }^{1}$ We shall denote by $p^{c}$ the market clearing price, i.e. $\sum_{i=0}^{n} s_{i}\left(p^{c}\right)=D\left(p^{c}\right)$. For some prices we might have zero supply whenever firm $i$ has fixed costs. The following assumption ensures that all firms will be active in the market.

Assumption 3. $s_{i}\left(p^{c}\right)>0$ for all $i \in \Omega$.

In our model firm 0 should play the role of the dominant firm, whereas the remaining firms should form the competitive fringe. We denote the set of these latter firms by $\Omega^{c}:=\{1,2, \ldots, n\}$ and we define $S^{c}:=\sum_{i=1}^{n} s_{i}$. According to Forchheimer the dominant firm sets its price by maximizing profit with respect to its residual demand curve $D^{r}(p):=\left(D(p)-S^{c}(p)\right)^{+}$. The set of prices maximizing $\pi^{r}:=D^{r}(p) p-c_{0}\left(D^{r}(p)\right)$ shall be denoted by $\Pi^{*}$. More specifically, the dominant firm chooses a price $p^{*} \in \Pi^{*}$, the other firms match price $p^{*}$ and the competitive fringe supplies $S^{c}\left(p^{*}\right)$.

The price actions of the producers' are given by $\mathbf{p}=\left(p_{0}, p_{1}, \ldots, p_{n}\right) \in$ $\left[p^{c}, b\right]^{n+1}$ that we will call from now on a price profile. The supply of producers $A \subset \Omega$ is given at price profile $\mathbf{p}$ by $\widehat{S}(\mathbf{p}, A):=\sum_{i \in A} s_{i}\left(p_{i}\right)$. Let

\footnotetext{
${ }^{1}$ There exists a unique price in case of fixed costs for which we have two profit maximizing quantities. For this price we define $s_{i}(p)$ as the larger one of these two quantities.
} 
$B(\mathbf{p}, i):=\left\{j \in \Omega \mid p_{j}<p_{i}\right\}$ and $C(\mathbf{p}, i):=\left\{j \in \Omega^{c} \mid p_{j}=p_{i}\right\}$. In our pricesetting game we assume efficient rationing of consumers (for more details on efficient rationing we refer to Tirole, 1988). Thus, we define the demand served by the firms in the following manner:

$$
\Delta_{i}(\mathbf{p}):=s_{i}\left(p_{i}\right) \min \left\{1, \frac{\left(D\left(p_{i}\right)-\widehat{S}(\mathbf{p}, B(\mathbf{p}, i))\right)^{+}}{\widehat{S}(\mathbf{p}, C(\mathbf{p}, i))}\right\}
$$

for any firm $i \in \Omega^{c}$ and

$$
\Delta_{0}(\mathbf{p}):=\min \left\{s_{0}\left(p_{0}\right),\left(D\left(p_{0}\right)-\widehat{S}(\mathbf{p}, B(\mathbf{p}, 0) \cup C(\mathbf{p}, 0))\right)^{+}\right\}
$$

for firm 0 . The definitions (1) and (2) assume that firm 0 serves the consumers at a given price level after the remaining firms have already sold their supply. We impose this assumption only for the technical reason of avoiding the need to have a competitive fringe setting their prices arbitrarily close to, but below, the dominant firm's price. Now we define the profit functions to be $\pi_{i}(\mathbf{p}):=p_{i} \Delta_{i}(\mathbf{p})-c_{i}\left(\Delta_{i}(\mathbf{p})\right)$ for all $i \in \Omega$.

Clearly, firm 0 can secure $\pi^{r}\left(p^{*}\right)$ profit, where $p^{*} \in \Pi^{*}$. Define the set $L:=$ $\left\{p \in[0, b] \mid p \min \left\{D(p), s_{0}(p)\right\}-c_{0}\left(\min \left\{D(p), s_{0}(p)\right\}\right)=\pi^{r}\left(p^{*}\right)\right\}$ consisting of those prices for which firm 0 is indifferent between serving the entire market or being a Forchheimer-type dominant firm. Note that $L$ is nonempty, but may contain more than one price. Let $p^{L}:=\inf L$. Firm 0 will never set its price below $p^{L}$ because any price $p<p^{L}$ is dominated by any price $p^{*} \in \Pi^{*}$. It can be easily checked that we have $p^{*}>p^{L}>p^{c}$ for any price $p^{*} \in \Pi^{*}$.

From now on we call firm 0 the large firm and the remaining firms small firms, which is justified by the following assumption.

Assumption 4. For all $i \in \Omega^{c}$ and all $p \in\left[p^{L}, b\right]$ we have

$$
D(p)-\sum_{j=1}^{n} s_{j}(p)+s_{i}(b)<s_{0}(p) .
$$

Assumption 4 ensures that if all firms with the exception of one small firm, which sets a higher price, set the same price $p \in\left[p^{L}, b\right]$, then the entire demand can be satisfied without this exceptional small firm.

\section{Endogenous timing of price decisions}

Suppose that the firms can choose between two time periods to make their price announcement. After the firms have made their timing decisions, which 
they all observe, they will play the corresponding price-setting game. A similar timing game has been investigated by Deneckere and Kovenock (1992) and by Hamilton and Slutsky (1990). First, we consider the case in which the large firm moves in period 1, while the remaining firms all move in period 2.

Proposition 1. If Assumptions 1-4 are fulfilled, the large firm moves first and the small firms second, then the subgame perfect Nash equilibria are given by $p_{i}^{*}=p^{*} \in \Pi^{*}$ for all $i \in \Omega$.

Proof. We already noted that the large firm will not set its price below $p^{L}$. Throughout this proof $\mathbf{p}$ stands for the profile in which every firm sets price $p$. We have to consider two different cases: (i) $S^{c}(p)<D(p)$, and (ii) $D(p) \leq$ $S^{c}(p)$. In the following $\bar{p}$ stands for the price satisfying equation $D(\bar{p})=$ $S^{c}(\bar{p})$.

In case (i) any firm $i \in \Omega^{c}$ will not set its price below $p$. Suppose that a price profile $\mathbf{p}^{\prime}$ with $p_{i}^{\prime} \geq p$ for all $i \in \Omega^{c}, \mathbf{p}^{\prime} \neq \mathbf{p}$, and $p_{0}^{\prime}=p$ is an equilibrium of the subgame. Let $p^{H}$ be the highest price in profile $\mathbf{p}^{\prime}$ and $A \subset \Omega^{c}$ be the set of those firms setting price $p^{H}$. Firms in $A$ cannot sell their entire supply because $p_{i}^{\prime}>p^{c}$ for all $i \in \Omega$. If the firms in $A$ sell nothing at all, then $\mathbf{p}^{\prime}$ cannot be an equilibrium profile. We claim that if firms in $A$ can sell their supply partly, then $A$ has at least two elements. Suppose that $A=\{j\} \subset \Omega^{c}$. Hence,

$$
\widehat{S}\left(\mathbf{p}^{\prime}, \Omega \backslash\{j\}\right) \geq s_{0}(p)+S^{c}(p)-s_{j}(b)>D(p)>D\left(p^{H}\right)
$$

because of (3); a contradiction. Thus, $A$ has at least two elements. Hence, any firm in $A$ is interested in undercutting $p^{H}$. Therefore, the only possible equilibrium of the subgame is $\mathbf{p}$. Moreover, $\mathbf{p}$ is an equilibrium of the subgame because if any producer raises its price unilaterally above $p$, then the demand it faces will be zero because of (3). Thus, the large firm sells $D(p)-S^{c}(p)$.

In case (ii) any firm $i \in \Omega^{c}$ will not set its price below $\bar{p}$, since at price $\bar{p}$ a firm in the fringe can sell its entire supply. In an analogous way to case (i) one can show that none of the small firms set their prices above $p$, which in turn implies that the large firm faces no demand at all and therefore, it will not set a price above or equal to $\bar{p}$.

Finally, we conclude that the large firm sets its price by maximizing $\pi^{r}$ because it chooses its price from $\left[p^{L}, \bar{p}\right]$ and for such prices the small firms behave as price takers.

Second, we turn to the simultaneous-move game, which has a mixedstrategy equilibrium by Maskin's (1986) Theorem $2 .^{2}$ The next theorem es-

\footnotetext{
${ }^{2}$ In the simultaneous-move game we do not have to define the demand for the large firm and the small firms differently as in (1) and (2).
} 
tablishes that Forchheimer's model does not emerge as an equilibrium outcome of our timing game.

Theorem 1. If $\varphi^{*}=\left(\varphi_{0}^{*}, \varphi_{1}^{*}, \ldots, \varphi_{n}^{*}\right)$ is a mixed-strategy equilibrium of the simultaneous-move price-setting game, then under Assumptions 1-4 we have

$$
\pi_{0}\left(\varphi_{0}^{*}, \varphi_{1}^{*}, \ldots, \varphi_{n}^{*}\right) \geq \pi_{0}\left(p^{*}, \varphi_{1}^{*}, \ldots, \varphi_{n}^{*}\right)>\pi^{r}\left(p^{*}\right)
$$

for all $p^{*} \in \Pi^{*}$, which implies that the large firm prefers playing the simultaneous-move price-setting game to accepting the role of the price leader.

Proof. Clearly, every firm $i \in \Omega$ setting price $p^{*} \in \Pi^{*}$ cannot be an equilibrium because then the large firm will slightly undercut price $p^{*}$. Observe that the large firm can sell in any mixed-strategy equilibrium at price $p^{*}$ more than $D^{r}\left(p^{*}\right)$ with probability one even if all small firms set prices lower than $p^{*}$ because of Assumption 2. Thus, $\pi_{0}\left(p^{*}, \varphi_{1}^{*}, \ldots, \varphi_{n}^{*}\right)>\pi^{r}\left(p^{*}\right)$. Obviously $\pi_{0}\left(\varphi_{0}^{*}, \varphi_{1}^{*}, \ldots, \varphi_{n}^{*}\right) \geq \pi_{0}\left(p^{*}, \varphi_{1}^{*}, \ldots, \varphi_{n}^{*}\right)$.

For the case of a sufficiently asymmetric duopoly game we could even determine the outcome of the two-period timing game (Tasnádi, 2003). However, for the oligopolistic case this turns out to be a very difficult task and remains an open problem.

\section{References}

[1] Deneckere, R. and D. Kovenock, 1992, Price Leadership, Review of Economic Studies 59, 143-162.

[2] Hamilton, J.H. and S.M. Slutsky, 1990, Endogenous Timing in Duopoly Games: Stackelberg or Cournot Equilibria, Games and Economic Behavior 2, 29-46.

[3] Maskin, E., 1986, The Existence of Equilibrium with Price-Setting Firms, American Economic Review 76, 382-386.

[4] Tasnádi, A., 2000, A price-setting game with a nonatomic fringe, Economics Letters 69, 63-69.

[5] Tasnádi, A., 2003, Endogenous timing of moves in an asymmetric pricesetting duopoly, Portuguese Economic Journal 2, 23-35.

[6] Tirole, J., 1988, The Theory of Industrial Organization (MIT Press, Cambridge MA) 